\title{
Activation experiment for concrete blocks using thermal neutrons
}

\author{
Koichi Okuno ${ }^{1 *}$, Seiichiro Tanaka ${ }^{1}$ \\ ${ }^{1}$ Hazama-Ando Corporation Technical Research Institute, Karima 515-1, Tsukuba, Ibaraki, 305-0822, Japan
}

\begin{abstract}
Activation experiments for ordinary concrete, colemanite-peridotite concrete, $\mathrm{B} 4 \mathrm{C}$-loaded concrete, and limestone concrete are carried out using thermal neutrons. The results reveal that the effective dose for gamma rays from activated nuclides of colemanite-peridotite concrete is lower than that for the other types of concrete. Therefore, colemanite-peridotite concrete is useful for reducing radiation exposure for workers.
\end{abstract}

\section{Introduction}

In recent years, applications of neutrons have been studied in various fields. Concrete is widely used for the neutron shields. Although concrete is inexpensive, it requires massive thickness to make enough shields to neutrons and to occupy the room spaces.

Boron carbide is a good neutron absorber and often used as the containing material for the concrete. But the cost of its shield has risen steeply because boron carbide has a very high cost.

Colemanite is an example of the natural rock that contains boron. It is produced in several places in the world, but most is produced in Turkey. The active research on concrete using colemanite as an aggregate was done in the 1950s and 1960s. ${ }^{(1)-(5)}$ Research on concrete blocks using colemanite was carried out. ${ }^{(6)-(9)}$ But, they cannot use facility.

Hydrogen-containing material is used for neutron shielding. Serpentinite and peridotite rocks contain much hydrogen. Serpentinite was used for neutron shielding concrete on the pedestal concrete shield on the reactor vessel in the fast breeder demonstration reactor Monju, ${ }^{(10)}$ but it is not desirable for outer shields now because serpentinite is also a raw material for asbestos.

To realize a compact shield satisfying the radiation dose criteria even in a limited space such as in a hospital, neutron shield concrete using colemanite and peridotite has been developed ${ }^{(11)}$. Such concrete has been used in four beam lines at the Materials and Life Science Facility (MLF) of the Japan Proton Accelerator Research Complex (J-PARC) and in the shielding wall of the RIKEN accelerator-driven compact neutron source (RANS) $^{(12)(13) \text {. }}$

In many cases, it is necessary to perform estimations of neutron activation for construction materials and research instruments. The influence of the activation is mainly divided into effects caused by the short half-life nuclides and those caused by the long half-life nuclides.
An increase in the ambient dose in a room after irradiation is caused by short half-life nuclides, and increased radioactive waste is caused by long half-life nuclides. In past research, many activation experiments for concrete have been carried out by concrete power that weighs around $100 \mathrm{mg}$ because the restriction of the irradiation port in research reactors. However, this method is not very realistic.

In this research, an activation experiment using various types of concrete blocks is carried out using thermal neutrons with an accelerator neutron source.

\section{Concrete blocks}

Ordinary concrete, colemanite-peridotite concrete (11), $\mathrm{B}_{4} \mathrm{C}$-loaded concrete, and limestone concrete are used in this research. Each concrete sample was made by us. The element analysis of each concrete was carried out by chemical analysis specifically ICP-AES (Inductively Coupled Plasma Atomic Emission Spectroscopy).

\subsection{Colemanite-peridotite concrete}

Colemanite-peridotite concrete uses colemanite and peridotite rocks as the aggregates. Colemanite is a natural mineral that is rich in boron in the form of $\mathrm{B}_{2} \mathrm{O}_{3}$. Peridotite is a natural mineral that is rich in hydrogen atoms in the form of $\mathrm{H}_{2} \mathrm{O}$. These minerals are used as aggregates, and together with ordinary Portland cement, form the colemanite-peridotite concrete. Colemanite forms 5-15 wt $\%$ of the concrete composition for improved shielding performance. The density of colemanite-peridotite concrete is the same as that of ordinary concrete.

The elemental analysis data for ordinary concrete and colemanite-peridotite concrete used in this research are presented in Tables 1 and 2.

\footnotetext{
* Corresponding author: okuno.koichi@ ad-hzm.co.jp
} 
Table 1. Ordinary concrete (wt\%)

\begin{tabular}{|c|c|c|c|c|c|}
\hline $\mathrm{SiO}_{2}$ & $\mathrm{H}_{2} \mathrm{O}$ & $\mathrm{MgO}$ & $\mathrm{MnO}$ & $\mathrm{Al}_{2} \mathrm{O}_{3}$ & $\mathrm{CaO}$ \\
\hline 62.4 & 4.73 & 1.36 & 0.06 & 10.4 & 10.2 \\
\hline $\mathrm{Na}_{2} \mathrm{O}$ & $\mathrm{K}_{2} \mathrm{O}$ & $\mathrm{TiO}_{2}$ & $\mathrm{Fe}_{2} \mathrm{O}_{3}$ & $\mathrm{SO}_{3}$ & \\
\hline 2.06 & 2.48 & 0.42 & 3.19 & 0.29 & \\
\hline
\end{tabular}

Table 2. Colemanite-peridotite concrete (wt\%)

\begin{tabular}{|c|c|c|c|c|c|}
\hline $\mathrm{SiO}_{2}$ & $\mathrm{H}_{2} \mathrm{O}$ & $\mathrm{MgO}$ & $\mathrm{MnO}$ & $\mathrm{Al}_{2} \mathrm{O}_{3}$ & $\mathrm{~B}_{2} \mathrm{O}_{3}$ \\
\hline 34.8 & 14.9 & 31.6 & 0.12 & 1.81 & 2.4 \\
\hline $\mathrm{CaO}$ & $\mathrm{Na}_{2} \mathrm{O}$ & $\mathrm{K}_{2} \mathrm{O}$ & $\mathrm{TiO}_{2}$ & $\mathrm{Fe}_{2} \mathrm{O}_{3}$ & $\mathrm{SO}_{3}$ \\
\hline 9.31 & 0.08 & 0.06 & 0.08 & 7.08 & 0.28 \\
\hline
\end{tabular}

\section{$2.2 \mathrm{~B}_{4} \mathrm{C}$-loaded concrete}

$\mathrm{B}_{4} \mathrm{C}$ (boron carbide)-loaded concrete contains $3 \mathrm{wt} \%$ of boron carbide powder loaded into ordinary concrete. The elemental analysis data for $\mathrm{B}_{4} \mathrm{C}$ loaded concrete used in this research are presented in Table 3.

Table 3. $\mathrm{B}_{4} \mathrm{C}$ loaded concrete (wt $\%$ )

\begin{tabular}{|c|c|c|c|c|c|}
\hline $\mathrm{SiO}_{2}$ & $\mathrm{H}_{2} \mathrm{O}$ & $\mathrm{MgO}$ & $\mathrm{MnO}$ & $\mathrm{Al}_{2} \mathrm{O}_{3}$ & $\mathrm{CaO}$ \\
\hline 49.6 & 3.07 & 1.34 & 0.07 & 9.46 & 15.4 \\
\hline $\mathrm{Na}_{2} \mathrm{O}$ & $\mathrm{K}_{2} \mathrm{O}$ & $\mathrm{TiO}_{2}$ & $\mathrm{Fe}_{2} \mathrm{O}_{3}$ & $\mathrm{C}$ & $\mathrm{B}$ \\
\hline 2.49 & 1.38 & 0.39 & 2.87 & 2.47 & 3.40 \\
\hline
\end{tabular}

\subsection{Limestone concrete}

Limestone concrete contains limestone as the coarse aggregate of the concrete. The fine aggregate used is ordinary sand. The elemental analysis data for limestone concrete used in this research are presented in Table 4.

Table 4. Limestone concrete (wt\%)

\begin{tabular}{|c|c|c|c|c|c|}
\hline $\mathrm{SiO}_{2}$ & $\mathrm{H}_{2} \mathrm{O}$ & $\mathrm{MgO}$ & $\mathrm{MnO}$ & $\mathrm{Al}_{2} \mathrm{O}_{3}$ & $\mathrm{CaO}$ \\
\hline 33.3 & 4.84 & 0.70 & 0.03 & 4.68 & 7.99 \\
\hline $\mathrm{Na}_{2} \mathrm{O}$ & $\mathrm{K}_{2} \mathrm{O}$ & $\mathrm{TiO}_{2}$ & $\mathrm{Fe}_{2} \mathrm{O}_{3}$ & $\mathrm{SO}_{3}$ & $\mathrm{CaCO}_{3}$ \\
\hline 0.92 & 0.99 & 0.17 & 1.47 & 0.29 & 46.0 \\
\hline
\end{tabular}

\section{Experimental Method}

Neutrons from the cyclotron accelerator with a beryllium target were used. Proton energy was $18 \mathrm{MeV}$; beam current was $17 \mu \mathrm{A}$. Thermal neutrons were obtained from the $90^{\circ}$ direction of the beryllium target with a polyethylene moderator and collimator. The size of each concrete sample was $45 \mathrm{~mm} \varphi \times 50 \mathrm{~mm}$ thickness, and the samples were piled up to a height of $150 \mathrm{~mm}$. To remove thermal neutrons other than those in the beam direction, a cadmium sheet was used around and at the bottom of the concrete sample. Thermal neutron flux irradiating the concrete sample was measured using gold foil. The experimental setup is shown in Figure 1. All the various concrete samples were irradiated at once, for the same time, i.e., $16 \mathrm{~h}$. In the BNCT treatment room, Neutron flux at the concrete wall that calculated by PHITS code is the order of $10^{6}\left(\mathrm{n} / \mathrm{cm}^{2} \mathrm{~s}\right)$, and treatment time is $1 \mathrm{~h}$, Therefore, integrated neutron flux is $3.6 \times$ $10^{9}\left(\mathrm{n} / 1 \mathrm{~h} \mathrm{~cm} \mathrm{~cm}^{2}\right)$. On the other hand, Neutron flux in experiment facility used in research is the order of $10^{5}$ $\left(\mathrm{n} / \mathrm{cm}^{2} \mathrm{~s}\right)$. So, The irradiation time equivalent to BNCT treatment is $16 \mathrm{~h}$. After irradiation, the gamma spectra of the concrete samples were measured by a Ge detector. Specification of $\mathrm{Ge}$ detector is $15 \%$ of efficiency, $1.9 \mathrm{keV}$ of resolution at ${ }^{60} \mathrm{Co}$. Then, quantitative analysis was carried out for all samples by using calibration data measured for a radioactive standard volume source. The measured activated nuclides are ${ }^{56} \mathrm{Mn}$ and ${ }^{24} \mathrm{Na}$, which are the most detected nuclides.

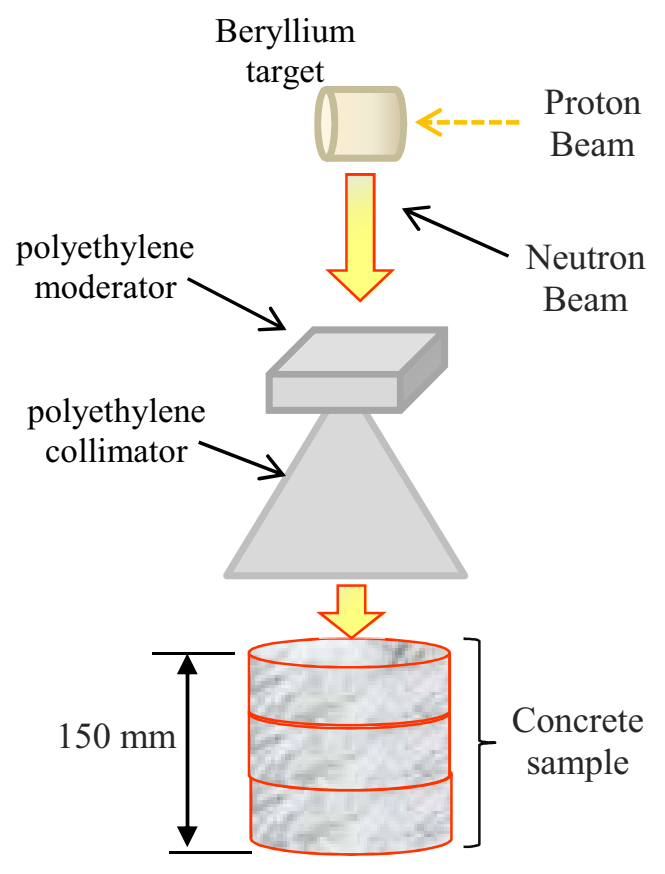

Experimental setup (sketch)

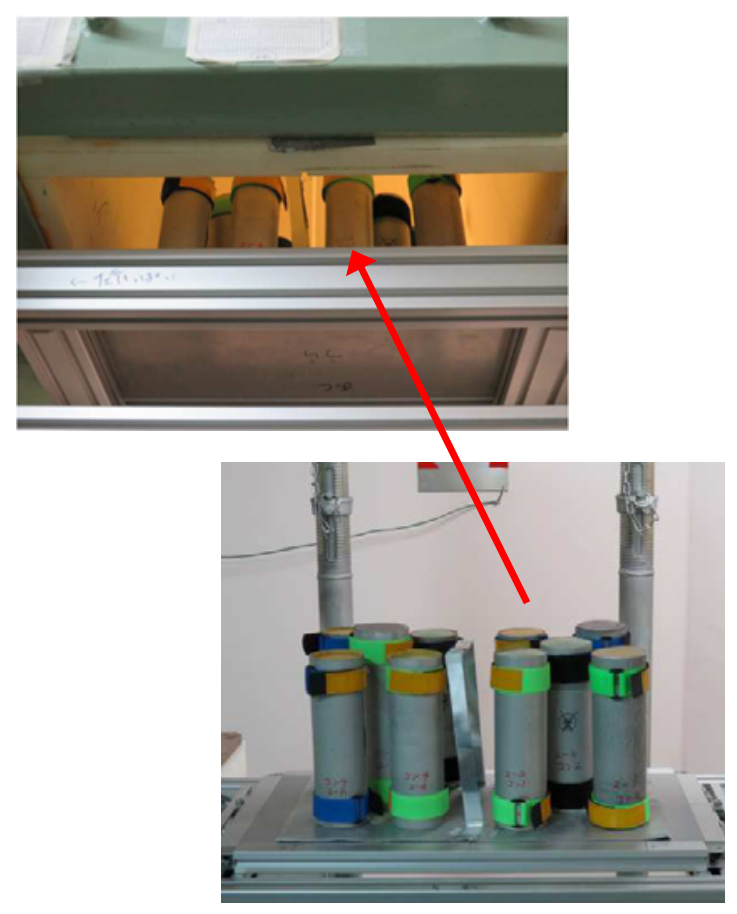

Experimental setup (picture)

Fig. 1. Experimental setup 


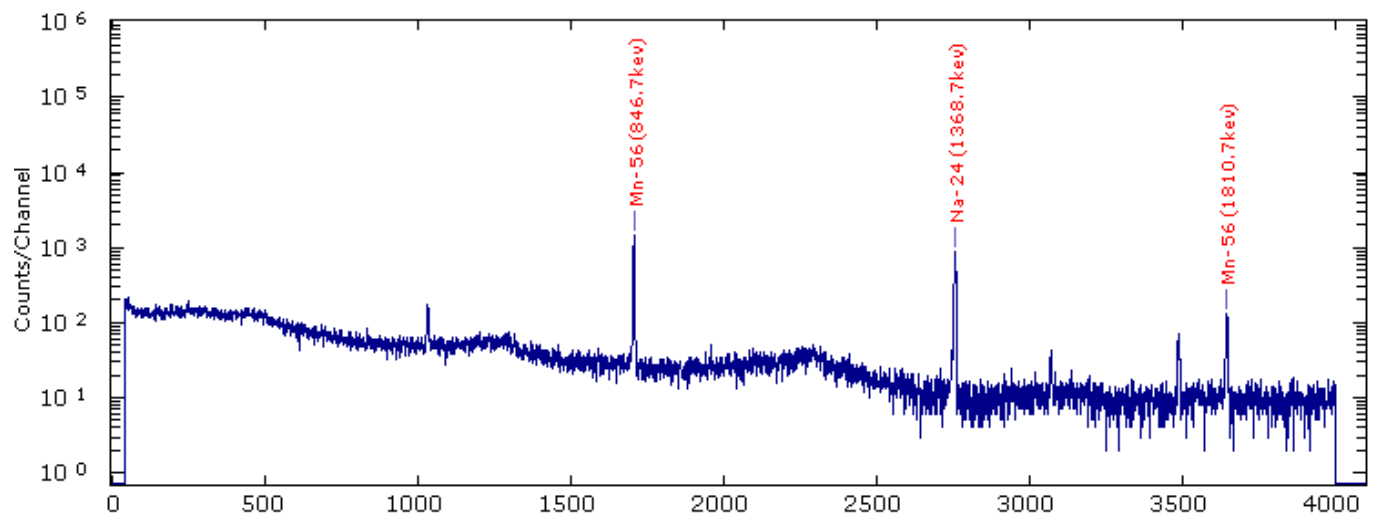

Fig. 2. Gamma spectrum for ordinary concrete (most closer to the neutron source)

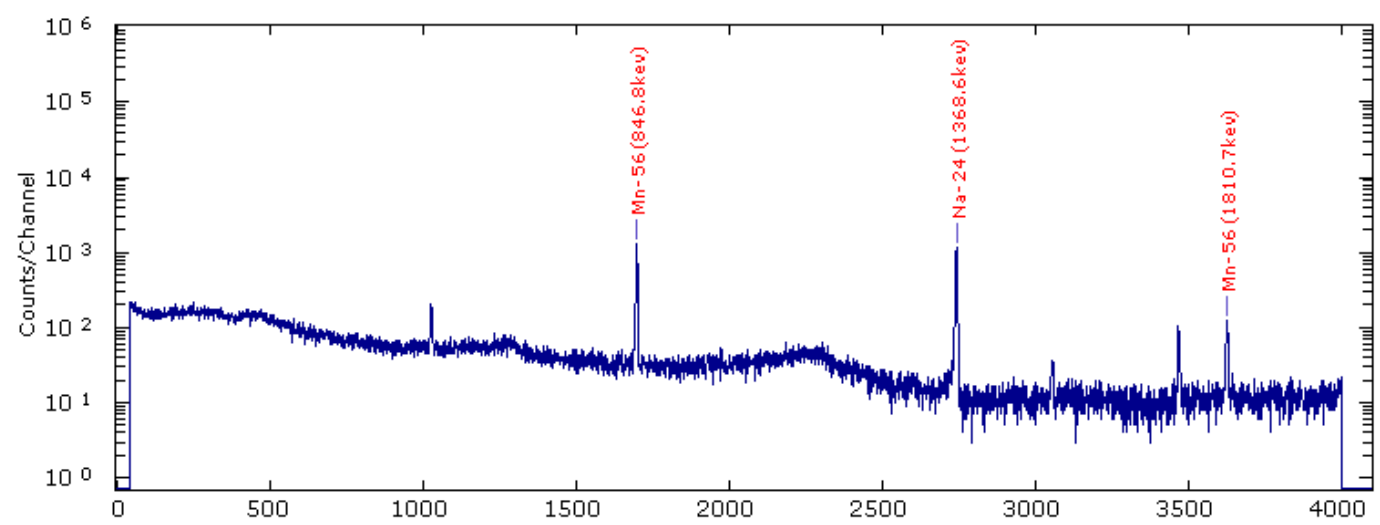

Fig. 3. Gamma spectrum for limestone concrete (most closer to the neutron source)

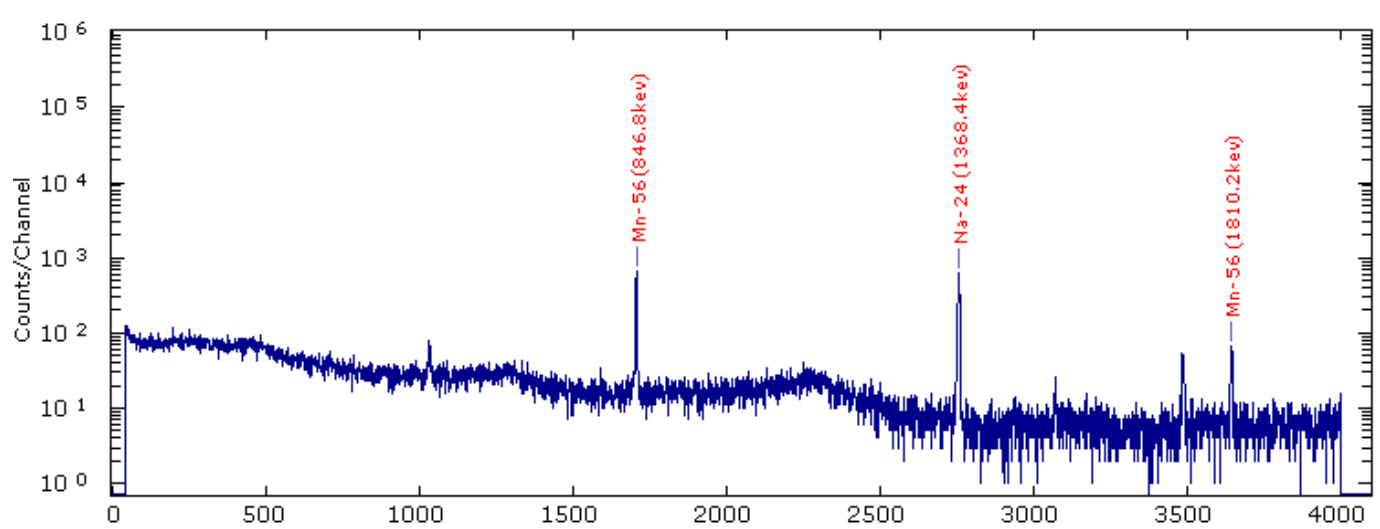

Fig. 4. Gamma spectrum for colemanite-peridotite concrete (most closer to the neutron source)

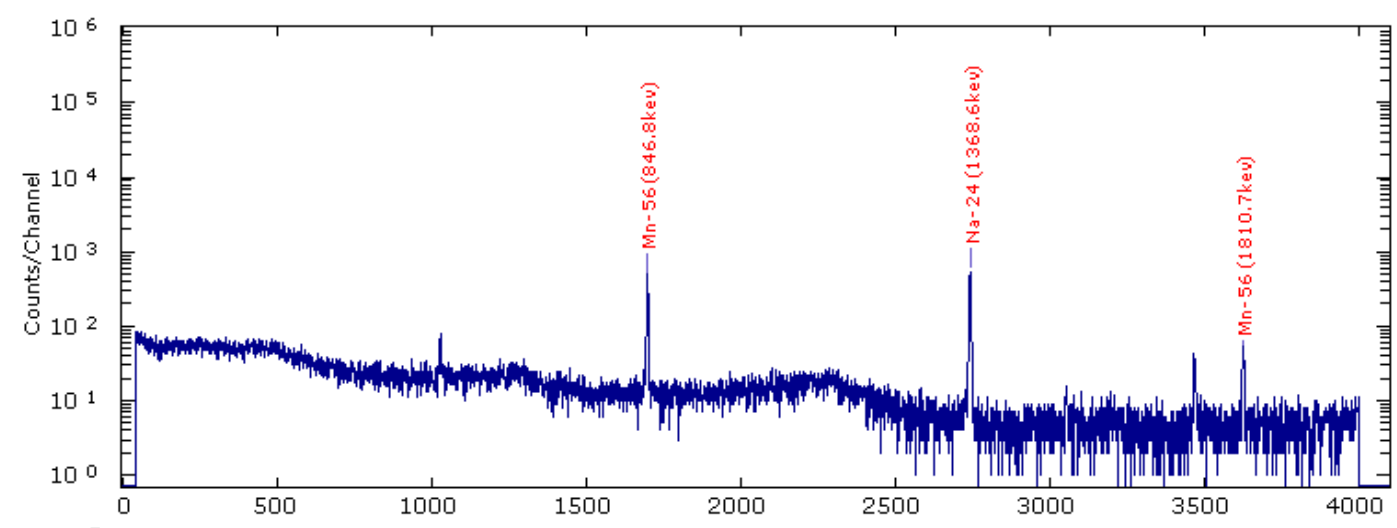

Fig. 5. Gamma spectrum for $\mathrm{B}_{4} \mathrm{C}-$-loaded concrete (most closer to the neutron source) 
Table 5. Results of quantitative analysis

\begin{tabular}{|c|c|c|}
\hline \multicolumn{3}{|c|}{ Ordinary concrete } \\
\hline Depth & ${ }^{56} \mathrm{Mn}(\mathrm{Bq} / \mathrm{g})$ & ${ }^{24} \mathrm{Na}(\mathrm{Bq} / \mathrm{g})$ \\
\hline $5 \mathrm{~cm}$ & 10.56 & 8.82 \\
\hline $10 \mathrm{~cm}$ & 1.31 & 1.02 \\
\hline
\end{tabular}

Table 6. Results of quantitative analysis

\begin{tabular}{|c|c|c|}
\hline \multicolumn{3}{|c|}{ Limestone concrete } \\
\hline Depth & ${ }^{56} \mathrm{Mn}(\mathrm{Bq} / \mathrm{g})$ & ${ }^{24} \mathrm{Na}(\mathrm{Bq} / \mathrm{g})$ \\
\hline $5 \mathrm{~cm}$ & 4.15 & 5.93 \\
\hline $10 \mathrm{~cm}$ & 0.55 & 0.70 \\
\hline
\end{tabular}

Table 7. Results of quantitative analysis

\begin{tabular}{|c|c|c|}
\hline \multicolumn{3}{|c|}{ Colemanite-peridotite concrete } \\
\hline Depth & ${ }^{56} \mathrm{Mn}(\mathrm{Bq} / \mathrm{g})$ & ${ }^{24} \mathrm{Na}(\mathrm{Bq} / \mathrm{g})$ \\
\hline $5 \mathrm{~cm}$ & 5.92 & 0.93 \\
\hline $10 \mathrm{~cm}$ & 0.39 & 0.47 \\
\hline
\end{tabular}

Table 8. Results of quantitative analysis

\begin{tabular}{|c|c|c|}
\hline \multicolumn{3}{|c|}{ B4C loaded conctete } \\
\hline Depth & ${ }^{56} \mathrm{Mn}(\mathrm{Bq} / \mathrm{g})$ & ${ }^{24} \mathrm{Na}(\mathrm{Bq} / \mathrm{g})$ \\
\hline $5 \mathrm{~cm}$ & 2.94 & 4.26 \\
\hline $10 \mathrm{~cm}$ & 0.30 & 0.30 \\
\hline
\end{tabular}

\section{Results}

The irradiated thermal neutron flux measured by the gold foil is $1.6 \times 10^{5}\left(\mathrm{n} / \mathrm{s} \mathrm{cm}^{2}\right)$ and the cadmium ratio is 5.4. Neutron spectra were not measured in this research because quantities of total thermal neutron are important for neutron activation in application facilities of neutrons. The measured gamma spectra at the top block of the concrete samples are shown in Figures 2-5. The live time in Figures $2-5$ is $600 \mathrm{~s}$ because measurement error is low enough. In Figures 2-5, a sharp peak of ${ }^{56} \mathrm{Mn}$ and ${ }^{24} \mathrm{Na}$ is seen for all concrete samples. The counts of gamma spectrum for concrete with boron are lower than that of concrete without boron. The results of quantitative analysis for each sample are shown in Tables 5-8. The amount of activation for ordinary concrete is the largest. The production amount of ${ }^{24} \mathrm{Na}$ and ${ }^{56} \mathrm{Mn}$ for limestone concrete, which has no boron content, was lower than that for ordinary concrete because elemental analysis data in table 4 were lower than ordinary concrete. For the concrete containing boron, i.e., colemanite-peridotite concrete, the $\mathrm{Mn}$ content was twice that of ordinary concrete, and four times that of limestone concrete. However, the amount of ${ }^{56} \mathrm{Mn}$ in colemanite-peridotite concrete was 1.4 times that of limestone concrete, and $44 \%$ lower than that of ordinary concrete. This is the effect of the neutron capture of boron. For the $\mathrm{B}_{4} \mathrm{C}$-loaded concrete, the amount of $\mathrm{Mn}$ and $\mathrm{Na}$ are almost the same as that of ordinary concrete. However, the amount of ${ }^{56} \mathrm{Mn}$ and ${ }^{24} \mathrm{Na}$ was respectively 3.6 and 2 times lower than that of ordinary concrete. This is also the effect of the neutron capture of boron.

\section{Conclusion}

Activation experiments for ordinary concrete, colemanite-peridotite concrete, $\mathrm{B}_{4} \mathrm{C}$-loaded concrete and limestone concrete were carried out. From the view of radiation protection, dose calculations for activated concrete shown in Tables 5-8 were carried out by PHITS code Ver.2.88 ${ }^{(14)}$. Nuclear data was used JENDL-4 ${ }^{(15)}$. Calculation model was assumed as shown in Figure 6.

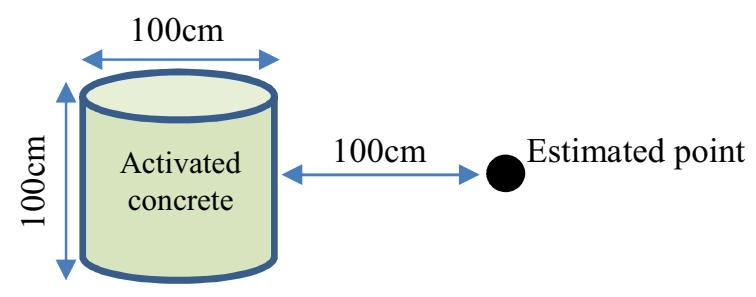

Fig. 6. Calculation model

Estimated point is $100 \mathrm{~cm}$ far from the activated concrete. Gamma ray energy data produce from activated nuclei were used the RI-source function in PHITS code. Flux to dose conversion factor was used built-in data of PHITS code. The effective doses at a distance of $100 \mathrm{~cm}$ from a activated concrete are listed in Table 9.

Table 9. Effective dose $(\mu \mathrm{Sv} / \mathrm{h})$

\begin{tabular}{|c|c|}
\hline Ordinary Concrete & Limestone Concrete \\
\hline 0.121 & 0.068 \\
\hline Colemanite-peridotite concrete & $\mathrm{B}_{4} \mathrm{C}$ loaded concrete \\
\hline 0.031 & 0.050 \\
\hline
\end{tabular}

Results reveal that the dose for gamma ray from activated nuclides of colemanite-peridotite concrete is lower than that for the other concrete types. The reason for this is considered to be derived from amount of ${ }^{24} \mathrm{Na}$. Gamma ray energy of ${ }^{24} \mathrm{Na}$ are $1.37 \mathrm{MeV}$ and $2.75 \mathrm{MeV}$, therefore, influence to dose is high. From the reslut, colemanite-peridotite concrete will be useful for reducing radiation exposure for workers. 


\section{References}

1. R. B. GALLAHER and A. S. KITZES, "Summary Report on Portland Cement Concretes for Shielding," ORNL-1414, Oak Ridge National Laboratory (1953)

2. A. N. KOMAROVSKII, Shielding Materials for Nuclear Reactors, Pergamon Press, New York (1961)

3. H. S.DAVIS, "High Density Concrete for Shielding Atomic Energy Plants," J. Am. Concrete. Inst., 54, 5,1965 (1958)

4. K. OKADA et al., "A Few Experiments for Shielding Concrete," in "Technical Annual Report for Cement," ,452 (1957) in Japanese

5. J. O. HENRIE, "Properties of Nuclear Shielding Concrete,”, J. Am. Concrete. Inst., 56, 7, 37 (1959)

6. Y. YARAR and A. BAYULKEN, "Investigation of Neutron Shielding Efficiency and Radioactivity of Concrete Shielding Containing Colemanite," J. Nuclear. Materials., 212-215, 1720 (1994)

7. D. E. VOLKMAN and P. L. BUSSOLINI, "Comparison of Fine Particle Colemanite and Boron Frit in Concrete for Time-Strength Relationship,” J. Test. Eval., 20, 92 (1992)

8. Berna Oto et al., Photon attenuation properties of some concretes containing barite and colemanite in different rates. Annals of Nuclear Energy 51 (2013) $120-124$

9. Turgay Korkut et al., Neutron dose transmission measurements for several new concrete samples including colemanite. Annals of Nuclear Energy 37 (2010) 996-998

10. S. USAMI, K. SASAKI, T. DESHUMARU, and F. NAKASHIMA," Measurement of Shielding Characteristics in the Prototype FBR Monju," J. Nucl. Sci. Technol., Suppl. 1, 83(2000)

11. Koichi Okuno, Masayoshi Kawai, Hitoshi Yamada, "Development of Novel Neutron Shielding Concrete", Nuclear Technology, 168, 545-552 (2009).

12. Masayoshi Kawai,Masao Yonemura,Shuki Torii,Takashi Mutoya,Kazuhiro Mori,Toshiharu Fkunaga,Koichi Okuno,Kazuo Takeda,Koji Niita and Takashi Kamiyama, "Novel monolayer shields of a neutron powder diffractometer SPICA at BL09 of J-PARC", Progress in Nuclear Science and Technology, 4, 156-159 (2014).

13. Koichi Okuno,Masayoshi Kawai,Hitoshi Yamada,Takenao Shinohara,Shin-ichi Takata,Junichi Suzuki,Kentaro Suzuya and Kazuya Aizawa, "Application of neutron shield concrete to neutron scattering instrument TAIKAN in J-PARC", Progress in Nuclear Science and Technology, 4, 619-622 (2014).

14. T. Sato, K. Niita, N. Matsuda, S. Hashimoto, Y. Iwamoto, S. Noda, T. Ogawa, H. Iwase, H. Nakashima, T. Fukahori, K. Okumura, T. Kai, S. Chiba, T. Furuta and L. Sihver, Particle and Heavy Ion Transport Code System PHITS, Version 2.52, J. Nucl. Sci. Technol. 50:9, 913-923 (2013)

15. K. Shibata, O. Iwamoto, T. Nakagawa, N. Iwamoto, A. Ichihara, S. Kunieda, S. Chiba, K.
Furutaka, N. Otuka, T. Ohsawa, T. Murata, H. Matsunobu, A. Zukeran, S. Kamada, and J. Katakura: "JENDL-4.0: A New Library for Nuclear Science and Engineering," J. Nucl. Sci. Technol. 48(1), 1-30 (2011). 